\title{
Combination of the histone deacetylase inhibitor depsipeptide and 5-fluorouracil upregulates major histocompatibility complex class II and p21 genes and activates caspase-3/7 in human colon cancer HCT-116 cells
}

\author{
KOUJI OKADA ${ }^{1,2}$, SHUKO HAKATA ${ }^{1}$, JUN TERASHIMA ${ }^{1}$, TOSHIE GAMOU ${ }^{1}$, \\ WATARU HABANO $^{1}$ and SHOGO OZAWA ${ }^{1}$
}

\begin{abstract}
${ }^{1}$ Department of Pharmacodynamics and Molecular Genetics, School of Pharmacy, Iwate Medical University, Yahaba-cho, Shiwa-gun, Iwate 028-3694; ${ }^{2}$ Department of Pharmacy, Iwate Prefectural Central Hospital, Morioka, Iwate 020-0066, Japan
\end{abstract}

Received December 29, 2015; Accepted July 14, 2016

DOI: $10.3892 / o r .2016 .5008$

\begin{abstract}
Epigenetic anticancer drugs such as histone deacetylase (HDAC) inhibitors have been combined with existing anticancer drugs for synergistic or additive effects. In the present study, we found that a very low concentration of depsipeptide, an HDAC inhibitor, potentiated the antitumor activity of 5-fluorouracil (5-FU) in a human colon cancer cell model using HCT-116, HT29, and SW48 cells via the inhibition of colony formation ability or cellular viability. Exposure to a combination of 5-FU $(1.75 \mu \mathrm{M})$ and $1 \mathrm{nM}$ depsipeptide for 24 and $48 \mathrm{~h}$ resulted in a 3- to 4 -fold increase in activated caspase-3/7, while 5-FU alone failed to activate caspase-3/7. Microarray and subsequent gene ontology analyses revealed that compared to 5-FU or depsipeptide alone, the combination treatment of 5-FU and depsipeptide upregulated genes related to cell death and the apoptotic process consistent with the inhibition of colony formation and caspase-3/7 activation.
\end{abstract}

Correspondence to: Professor Shogo Ozawa, Department of Pharmacodynamics and Molecular Genetics, School of Pharmacy, Iwate Medical University, 2-1-1 Nishitokuta, Yahaba-cho, Shiwa-gun, Iwate 028-3694, Japan

E-mail: sozawa@iwate-med.ac.jp

Abbreviations: IARC, International Agency for Research on Cancer; CRC, colorectal cancer; 5-FU, 5-fluorouracil; TS, thymidylate synthase; DNMT, DNA methyltransferase; HDAC, histone deacetylase; Dep, depsipeptide; CTCL, cutaneous T-cell lymphoma; RLU, relative light unit; TYMS, thymidylate synthase gene; qRT-PCR, quantitative reverse-transcription polymerase chain reaction; SEM, standard error of mean; ANOVA, analysis of variance; $\mathrm{MHC}$, major histocompatibility complex; $\mathrm{ACTB}, \beta$-actin

Key words: histone deacetylase inhibitor, depsipeptide, 5-fluorouracil, combination, human colon cancer HCT-116, major histocompatibility complex class II genes, caspase-3/7 activation, p21 (CDKN1A), microarray analysis
These analyses indicated marked upregulation of antigen processing and presentation of peptide or polysaccharide antigen via major histocompatibility complex (MHC) class (GO:0002504) and MHC protein complex (GO:0042611). Compared with vehicle controls, the cells treated with the combination of 5-FU and depsipeptide showed marked induction (3- to 8.5-fold) of expression of MHC class II genes, but not of MHC class I genes. Furthermore, our global analysis of gene expression, which was focused on genes involved in the molecular regulation of MHC class II genes, showed enhancement of pro-apoptotic PCAF and CIITA after the combination of 5-FU and depsipeptide. These results may indicate a closer relationship between elevation of MHC class II expression and cellular apoptosis induced by the combination of depsipeptide and 5-FU. To the best of our knowledge, this is the first study to report that the combination of 5-FU and depsipeptide induces human colon cancer cell apoptosis in a concerted manner with the induction of MHC class II gene expression.

\section{Introduction}

The International Agency for Research on Cancer (IARC) reported that colorectal cancer (CRC) is the third most commonly diagnosed cancer and the fourth leading cause of cancer-related death worldwide. Drug combinations and administration protocols, and the development of molecular targeted drugs have greatly improved the chemotherapeutic efficiency for CRC.

Fluoropyrimidines, especially 5-fluorouracil (5-FU), remain the most important chemotherapeutic agents in the treatment of CRC. 5-FU is reported to induce cellular toxicity by inhibiting its target enzyme, thymidylate synthase (TS); it also induces cell cycle arrest and apoptosis via the incorporation of fluoronucleotides into RNA and DNA leading to thymidylate depletion (1). 5-FU is the central component in the FOLFIRI regimen with the addition of irinotecan, and the FOLFOX regimen with the addition of oxaliplatin. These combination chemotherapies have resulted in improved response rates and significant improvements in progression-free 
and overall survival $(2,3)$. However, despite recent advances in CRC chemotherapy, the occurrence of drug resistance hinders effective control of the disease. Moreover, most advanced CRC patients cannot be cured with these refined chemotherapies.

Histone acetylation and deacetylation are biological processes that regulate the modification of chromatin structures and are important for gene regulation. Recently, a number of anticancer drugs such as inhibitors of DNA methyltransferase (DNMT) and histone deacetylase (HDAC) have been developed. DNMT and HDAC inhibitors cause DNA demethylation and repressive complex disintegration. This leads to the reactivation of critical genes and the reversal of genome-wide epigenetic alterations in cancer through resetting multiple cellular processes including, lineage commitment, immunomodulation, major cell signaling pathways, cell proliferation, and cell death $(4,5)$. Overexpression or underexpression of pro-apoptotic and anti-apoptotic molecules, such as p53 and Bcl-2, can be modulated by various HDAC inhibitors (6). Inhibitors of HDACs are known to exert effects including apoptosis, retardation of cell cycle progression, and cancer cell differentiation, which are specific depending on cancer cell type $(7,8)$. Therefore, a number of HDAC inhibitors have been investigated clinically. Vorinostat, entinostat, panobinostat, valproic acid, depsipeptide, and belinostat have been approved and clinically used. HDAC inhibitors are also used in combination therapy with DNMT inhibitors and other HDAC inhibitors (9). A basic study on combinations of valproic acid and gemcitabine has also been conducted (10).

DNMT inhibitors, such as 5-azacytidine, 5-aza-2'-deoxycytidine, and zebularine have been studied for various cancers in clinical trials (11). The therapeutic benefits of HDAC inhibitors have been verified as a monotherapy for cutaneous T-cell lymphoma (CTCL), and in other malignancies (12). Epigenetic agents are also known to have the ability to reverse the resistance of anticancer drugs $(13,14)$. Furthermore, synergistic or additive effects have been reported when combining epigenetic agents with existing anticancer drugs (15-17).

Depsipeptide (Dep, also known as FR901228, FK228 and romidepsin), isolated from Chromobacterium violaceum strain WB968, is a unique bicyclic peptide with a non-cysteine disulfide bridge. It is a stable prodrug, which is activated by reduction in cancer cells, to inhibit HDAC class I enzymes, and has been shown to convert H-ras-transformed NIH 3T3 cells to normal morphology. Thus, Dep is a promising anticancer agent, and indeed, has been approved by the FDA for the treatment for CTCL and peripheral T-cell lymphoma $(18,19)$. The glutathione-mediated activation also implicates its clinical usefulness for counteracting glutathione-mediated drug resistance in chemotherapy (20).

In addition to their use as monotherapy, there are several studies on the effects and mechanisms of the combination of 5-FU and HDAC inhibitors for CRC treatment. Lee et al reported that trichostatin A enhanced 5-FU cytotoxicity by downregulating the expression of both TYMS mRNA and TS protein in colon cancer cells (21). Tumber et al reported that belinostat, an HDAC inhibitor, synergized with 5-FU to inhibit colon cancer cell growth in vitro and in vivo, and this combination therapy increased DNA fragmentation and poly(ADP-ribose) polymerase cleavage and downregulated TYMS in HCT116 cells (22). Di Gennaro et al found that modulation of TYMS and p53 expression by vorinostat resulted in synergistic antitumor effects in combination with 5-FU or raltitrexed (23). Fazzone et al reported that panobinostat suppressed TYMS gene expression and synergized with fluoropyrimidines in colon cancer cells (24). Little is known concerning the combinatorial effects of 5-FU and Dep for $\mathrm{CRC}$, which prompted us to investigate the combination of HDAC inhibitors, namely, Dep, apicidin, and oxamflatin, with 5-FU. We previously found that among these HDAC inhibitors, Dep potentiated the cytotoxicity of 5-FU against human colon cancer cells, HCT-116.

Thus, in the present study, we aimed to evaluate the mode of the combined effect of 5-FU and Dep in HCT-116 cells (i.e., additive or synergistic), and to elucidate the genetic mechanism of the drug-drug interaction in a cell-based model using microarray analysis.

\section{Materials and methods}

Cell culture and reagents. Human colon carcinoma HCT-116 (no. CCL-247) , HT29 (no. HTB-38) and SW48 cell lines (no. CCL-231) [all from American Type Culture Collection (ATCC), Manassas, VA, USA] were cultured in Dulbecco's modified Eagle's medium (DMEM; 4.5 g/l D-glucose; Gibco, Grand Island, NY, USA) and supplemented with $10 \%$ fetal bovine serum (HyClone, South Logan, VT, USA) and antibiotics (Gibco) at $37^{\circ} \mathrm{C}$ in a $\mathrm{CO}_{2}$ incubator. Dep was purchased from Selleck Chemicals LLC (Houston, TX, USA). 5-FU was purchased from Sigma Chemical Co. (St. Louis, MO, USA). All other chemicals used were of the highest grade available.

Drug exposure. HCT-116 cells were exposed for 7 days to either vehicle alone, 5-FU alone, Dep alone, or a combination of 5-FU and Dep for assessment of inhibition of colony formation and gene expression analysis. The concentrations used for colony formation analysis were $0.875,1.25,1.75$ and $2.5 \mu \mathrm{M}$ for 5-FU; $0.5,1,1.5$ and $2 \mathrm{nM}$ for Dep; and $0.875 \mu \mathrm{M} 5-\mathrm{FU}$ plus Dep (0.1 or $1 \mathrm{nM}), 1.25 \mu \mathrm{M} 5$-FU plus Dep (0.1 or $1 \mathrm{nM})$, and $1.75 \mu \mathrm{M} 5$-FU plus Dep (0.1 or $1 \mathrm{nM})$. Concentrations used for gene expression analysis and caspase-3 activation assay were $1.75 \mu \mathrm{M}$ for 5-FU; $1 \mathrm{nM}$ for Dep; and $1.75 \mu \mathrm{M}$ 5-FU plus Dep $1 \mathrm{nM}$.

HT29 cells were exposed for 10 days to either vehicle alone, 5-FU alone, Dep alone, or a combination of 5-FU and Dep for assessment of inhibition of colony formation. The concentrations used for colony formation analysis were $0.313,0.438$, 0.625 and $0.875 \mu \mathrm{M}$ for 5-FU; $0.125,0.25,0.375$ and $0.5 \mathrm{nM}$ for Dep; and $0.313 \mu \mathrm{M} 5$-FU plus Dep $(0.375 \mathrm{nM}), 0.438 \mu \mathrm{M}$ 5-FU plus Dep (0.375 nM), and 0.625 $\mu \mathrm{M}$ 5-FU plus Dep (0.375 nM).

SW48 cells were exposed for 7 days to either vehicle-only, 5-FU alone, Dep alone, or a combination of 5-FU and Dep for crystal violet assay. The concentrations used for the crystal violet assay were, $0.438,0.625,0.875$ and $1.75 \mu \mathrm{M}$ for 5 -FU; $0.125,0.25,0.375$ and $0.5 \mathrm{nM}$ for Dep; and $0.438 \mu \mathrm{M} 5-\mathrm{FU}$ plus Dep (0.2 nM), $0.625 \mu \mathrm{M} 5$-FU plus Dep (0.2 nM), and $0.875 \mu \mathrm{M} 5$-FU plus Dep (0.2 nM).

Colony formation assay. HCT-116 cells were trypsinized, counted, and seeded for the colony formation assay in 60-mm 
Table I. Nucleotide sequences of the oligonucleotide primers used for determining mRNA levels in quantitative real-time PCR.

\begin{tabular}{llll}
\hline Accession no. & Gene symbol & \multicolumn{1}{c}{ Forward primer (5'-3') } & \multicolumn{1}{c}{ Reverse primer (3'-5') } \\
\hline NM_001101 & ACTB & GGCACCACACCTTCTACAATGAG & GGATAGCACAGCCTGGATAGCA \\
NM_001188 & BAK1 & TGAAAAATGGCTTCGGGGCAAGGC & TCATGATTTGAAGAATCTTCGTACCA \\
NM_138763 & BAX & GGCCCACCAGCTCTGAGCAGA & GCCACGTGGGCGTCCCAAAGT \\
NM_000633 & BCL2 & CGACTTCGCCGAGATGTCCAG & ACTTGTGGCCCAGATAGGCACCCAG \\
NM_000389 & CDKN1A (p21) & CAAGCTCTACCTTCCCACGG & GGTAGAAATCTGTCATGCTGGTC \\
NM_000077 & CDKN2A (p16) & ATGGAGCCTTCGGCTGACT & ATCATCATGACCTGGATCGGC \\
NM_004964 & HDAC1 & GCTCCATCCGTCCAGATAAC & TGCCACAGAACCACCAGTAG \\
NM_002116 & HLA-A & CAGCTTGTAAAGTGTGAGACAGC & GGAAAGATGATTGGGGAGGGAG \\
NM_005514 & HLA-B & GTAGGAGGAAGAGTTCAGGTGG & ACATTATGCTAACAGGGACGCA \\
NM_002117 & HLA-C & CTGGTTGTCCTAGCTGTCCTTG & AGCTGTCTCAGGCTTTACAAGTG \\
NM_002121 & HLA-DPB1 & TCCACCAACCTGATCCGTAATG & AGAATCAGACTGTGCCTTCCAC \\
NM_002123 & HLA-DQB1 & CAAAGGAGTCAGAAAGGGCTTC & GGGGATGAAAGGAGATGACCTG \\
NM_019111 & HLA-DRA & CCGATCACCAATGTACCTCCAG & CAGGAAGGGGAGATAGTGGAAC \\
NM_002124 & HLA-DRB1 & CTCACAGTGGAATGGAGAGCAC & GAATAACTGCCAAGCAGGAAAGC \\
NM_000546 & TP53 & GCTCAGATAGCGATGGTCTGG & GATGGTGGTACAGTCAGAGCC \\
NM_001071 & TYMS & GTTGCTGTGGTTTATCAAGGGAT & TTGGTCAACTCCCTGTCCTG \\
\hline
\end{tabular}

dishes at 20,000 cells/dish. HT29 cells were trypsinized, counted, and seeded for the colony formation assay in 60-mm dishes at 10,000 cells/dish. After incubation for 7 to 10 days, the colonies were stained with crystal violet and the numbers of positive colonies were counted. Colonies containing more than 50 cells were regarded as positive and were scored, and each assay was conducted in triplicate and three separate assays were performed on three different days.

Crystal violet assay. We measured cell viability in SW48 cells by direct staining of the cells using crystal violet assay (25) as SW48 cells have poor colony-forming ability. SW48 cells were trypsinized, counted, and seeded for the crystal violet assay in 6-well plate at 50,000 cells/well. After incubation for 7 days, the medium was removed and any adherent cells were fixed to the plate with $10 \%$ formaldehyde in PBS. The cells were then stained with an aqueous solution of $0.5 \%$ crystal violet followed by elution of the dye with $33 \%$ aqueous acetic acid. Absorbance at $550 \mathrm{~nm}$ was determined with a microplate reader, Infinite F500 (Tecan Group Ltd., Männedorf, Switzerland). Each assay was conducted in triplicate and three separate assays were performed on three different days.

Caspase-3/7 activation assay. Luminescent caspase-3/7 activation assay was conducted according to the manufacturer's instructions (Caspase-Glo ${ }^{\mathrm{TM}}$ 3/7 assay; Promega, Madison, WI, USA). HCT-116 cells were inoculated into each well of a white-walled 96-well plate (4,000 cells/well), treatment reagents were added and incubated was carried out for 0,24 and $48 \mathrm{~h}$. After incubation for $1 \mathrm{~h}$ with Caspase- $\mathrm{Glo}^{\mathrm{TM}}$ reagent, the enzymatic activity of caspase-3/7 was measured using a microplate reader, Infinite F500 (Tecan Group Ltd.). The background luminescence associated with the cell culture and assay reagent (blank reaction) was subtracted from the experimental values. Mean values of four replicates were used to represent caspase$3 / 7$ activity. To enable normalization of data to total cellular protein content, the Lowry assay (26) was conducted for all samples according to the manufacturer's instructions (Protein Assay Lowry kit; Nacalai Tesque, Kyoto, Japan). Data are expressed as relative light units (RLU) $/ \mu \mathrm{g}$ of protein.

RNA extraction and quantitative reverse-transcription polymerase chain reaction ( $q R T-P C R$ ). Total RNA was extracted from three independent HCT-116 cell cultures using the RNeasy Mini kit following the manufacturer's instructions (Qiagen, Dusseldorf, Germany). Total RNAs (1 $\mu \mathrm{g})$ were used for cDNA synthesis using a cDNA synthesis kit (Roche, Basel, Switzerland). Using first-strand cDNA, real-time PCR was performed using a 7500 Real-Time PCR system (Applied Biosystems, Tokyo, Japan). The sequences of amplification primers are shown in Table I.

Microarray analysis. For DNA microarray analysis, total RNA (50 ng) was labeled with cyanine-3 using a Low Input Quick Amp Labeling kit (Agilent Technologies, Inc., Santa Clara, CA, USA). The labeled targets were hybridized to SurePrint G3 Human 8x60K oligo DNA microarrays and hybridized microarrays were scanned using an Agilent Microarray Scanner (both from Agilent Technologies, Inc.). Image analysis and raw array data generation were processed using Feature Extraction software (Agilent Technologies, Inc.). Normalization of the raw array data was performed using GeneSpring software.

Gene ontology analysis. Following quantile normalization of the raw data, data sets were further reduced by filtering noise of the signal, including gIsSaturated, gIsFeatNonUnifOL, gIsFeatPopnOLg, and gIsWellAboveBG.

Finally, we identified gene lists that showed at least 1.5-fold upregulation or downregulation.

The PANTHER classification system (www.pantherdb. org/tools/genex Analysis.jsp) was used for functional classification of genes. 
Mi et al discussed the procedure for classification of proteins using PANTHER, a web tool for analyzing protein family trees and functions (27). The overall process of PANTHER Protein Library data generation consisted of three major steps: family clustering, phylogenetic tree building, and annotation of tree nodes. The requirements for being family clusters in PANTHER are as follows:

i) The family must contain at least five members among which at least one gene must be listed as a Gene Ontology (GO) reference genome.

ii) In order to support phylogenetic inference, the family should be aligned with high quality sequence data.

iii) A certain length of aligned sequences stored in at least 30 sites should be aligned across $75 \%$ or more of the family members for creation of proper family clusters.

A statistical enrichment test was performed for each molecular function, biological process, or cellular component. The genes associated with a particular ontology term were evaluated according to the likelihood of the numerical values of genes that were drawn randomly from the overall distribution of values. The Mann-Whitney U test was used to determine the P-value. A number of genes, which were induced in large extent by our microarray analysis, were classified according to a number of statistical tests that were performed by the PANTHER classification system. As a result, PANTHER classification concluded that induction of a considerable number of major histocompatibility complex (MHC) class II genes was a characteristic change in global gene expression caused by the present drug combination of 5-FU and Dep (discussed in Results). The details of using this tool are described in the PANTHER user manual for PANTHER 9.0.

Statistical analysis. Data are represented as the mean \pm standard error of mean (SEM) and analyzed for statistical significance using one-way analysis of variance (ANOVA) followed by the Tukey-Kramer test as a post hoc test. A P-value of $<0.05$ was considered to indicate a statistically significant result.

\section{Results}

Cellular sensitivity of the HCT-116 cells to 5-FU. The approximate $\mathrm{IC}_{50}$ value of the HCT-116 cells to 5-FU was $1.90 \mu \mathrm{M}$. However, Dep was almost 2,000-fold active in terms of molar concentration to inhibit colony formation ability of HCT-116 compared with 5-FU. Fig. 1A and B shows the dose-response curves of 5-FU and Dep, respectively. Fig. 1C shows the reduction of survival fraction for the combination of 5-FU and Dep, 5-FU alone, and Dep alone. The combination of $1.75 \mu \mathrm{M} 5-\mathrm{FU}$ and $1 \mathrm{nM}$ Dep suppressed colony formation to $30 \%$ compared with vehicle-only. This combination suppressed colony formation ability with statistical significance compared with 5-FU only $(\mathrm{P}<0.01)$. HCT-116 cells became less sensitive to $5-\mathrm{FU}$ in combination with $0.1 \mathrm{nM}$ Dep compared with 5-FU only, which was not marked.

Cellular sensitivity of the HT29 cells to 5-FU. The approximate $\mathrm{IC}_{50}$ value of HT29 to 5-FU was $0.68 \mu \mathrm{M}$. However, Dep was almost 2,000-fold active in terms of molar concentration to inhibit colony formation ability of HT29 cells compared with 5-FU. Fig. 1D and E shows the dose-response curves of 5-FU and Dep, respectively. Fig. 1F illustrates the reduction in survival fraction for the combination of 5-FU and Dep, 5-FU alone, and Dep alone. The combination of $0.625 \mu \mathrm{M} 5-\mathrm{FU}$ and $0.375 \mathrm{nM}$ Dep suppressed colony formation to $35 \%$ compared with vehicle-only. This combination suppressed colony formation ability with statistical significance compared with 5-FU-only $(\mathrm{P}<0.01)$.

Cellular sensitivity of the SW48 cells to 5-FU. The approximate $\mathrm{IC}_{50}$ value of SW48 to 5-FU was $1.15 \mu \mathrm{M}$. However, Dep was almost 5,000-fold active in terms of molar concentration to inhibit cellular viability of the SW48 cells compared with 5-FU. Fig. $1 \mathrm{G}$ and $\mathrm{H}$ shows the dose-response curves of 5-FU and Dep, respectively. Fig. 1I illustrates the reduction in survival fraction for the combination of 5-FU and Dep, $5-\mathrm{FU}$ alone, and Dep alone. The combination of $0.875 \mu \mathrm{M}$ 5-FU and $0.2 \mathrm{nM}$ Dep suppressed cellular viability to $25 \%$ compared with vehicle alone. This combination suppressed cellular viability with statistical significance compared with 5-FU alone $(\mathrm{P}<0.01)$.

Caspase-3/7 activation in HCT-116 cells following treatment with 5-FU (1.75 $\mu M)$ alone, Dep (1 nM) alone, and a combination of 5-FU and Dep. As shown in Fig. 2, the time course of caspase-3/7 activation was examined in the HCT-116 cells following treatment with 5-FU $(1.75 \mu \mathrm{M})$ alone, Dep $(1 \mathrm{nM})$ alone, and the combination of 5-FU and Dep.

At $24 \mathrm{~h}$, the combination of 5-FU and Dep markedly enhanced caspase-3/7 activation compared to the vehicle control (3.8-fold-change, $\mathrm{P}<0.01)$. Dep alone also showed a 2.0-fold increase $(\mathrm{P}<0.01)$ compared to the vehicle control.

At $48 \mathrm{~h}$, the combination of 5-FU and Dep increased caspase-3/7 activation compared to the vehicle control (2.8-fold-change, $\mathrm{P}<0.01)$. 5-FU alone and Dep alone slightly increased caspase- $3 / 7$ activation compared to the vehicle control (1.4-fold, $\mathrm{P}<0.05$; and 1.5-fold, $\mathrm{P}<0.01$, respectively).

Comparison of the gene expression profile and gene ontology of the cells treated with the control and 5-FU $(1.75 \mu M)+$ Dep ( $1 \mathrm{nM}$ ) combination. To examine the gene expression profile after drug exposure, we conducted a microarray analysis of the cells treated for 7 days with the vehicle control, 5-FU alone, Dep alone, and the combination of 5-FU with Dep as described in Materials and methods. Results of the gene expression profile were analyzed by gene ontology in order to clarify what mRNAs were upregulated (Table II) or downregulated (Table III) after treatment with each drug alone or with combination of 5-FU and Dep. To indicate the biological significance of cellular processes affected by the combination treatment, we listed the fold enrichment in descending order in Tables II and III.

Analysis of PANTHER GO-Slim Biological Process and Cellular Component revealed a marked increase in mRNA levels of MHC class-related gene ontologies (GO:000254 and GO:0042611, respectively).

The mechanism of action, cell cycle-and apoptosis-related gene expression in HCT-116 cells following treatment with 5-FU (1.75 $\mu \mathrm{M})$ alone, Dep (1 nM) alone, and combination 
A

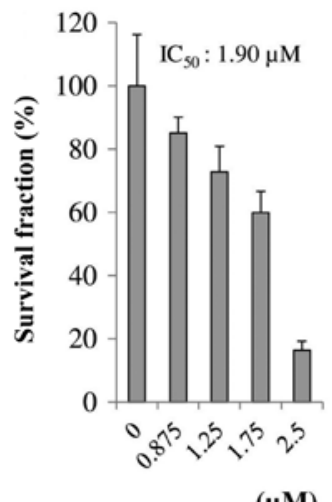

B

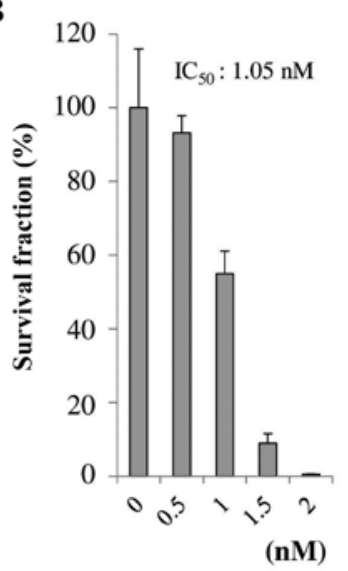

C

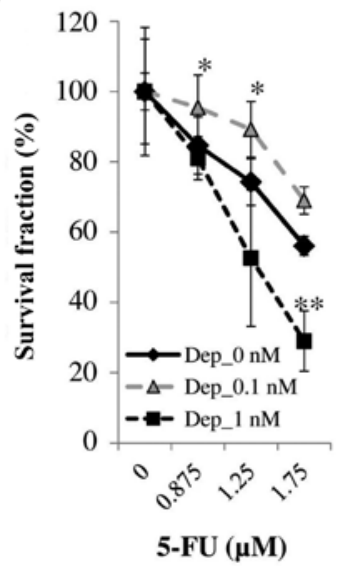

D

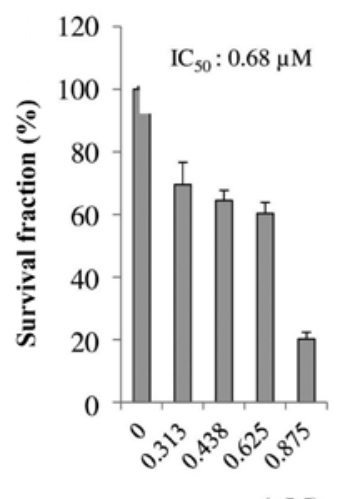

$(\mu \mathrm{M})$

E

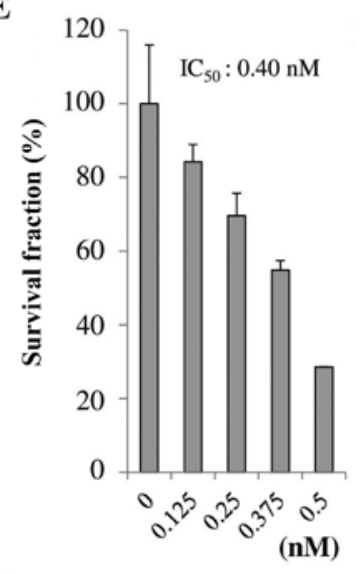

F

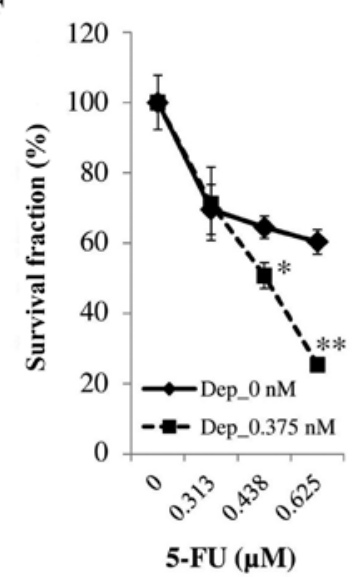

G

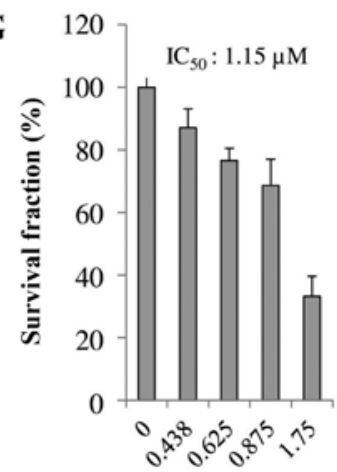

( $\mu \mathrm{M})$

H

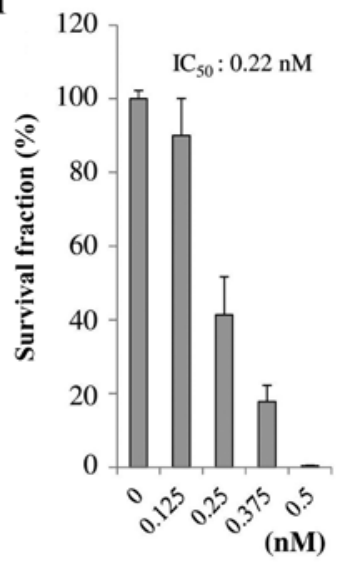

I

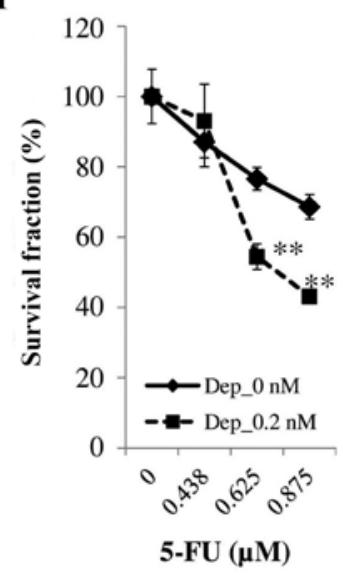

Figure 1. Effect of (A) 5-fluorouracil (5-FU), (B) depsipeptide (Dep) and the combination of (C) 5-FU and Dep on the inhibition of colony formation ability of human colon cancer HCT-116 cells. Effect of (D) 5-FU, (E) Dep and the combination of (F) 5-FU and Dep on the inhibition of colony formation ability of human colon cancer HT29 cells. Effect of (G) 5-FU, (H) Dep and the combination of (I) 5-FU and Dep on inhibition of cellular viability of the human colon cancer SW48 cells. The $\mathrm{x}$-axis represents drug concentrations, and y-axis represents survival fraction (i.e., colony-forming ability relative to $0 \mu \mathrm{M}$ 5-FU). ${ }^{*} \mathrm{P}<0.05$ vs. $0 \mathrm{nM}$ Dep, ${ }^{* *} \mathrm{P}<0.01$ vs. $0 \mathrm{nM}$ Dep by one-way ANOVA.



Figure 2. Time-course of caspase-3/7 activation in HCT-116 cells following treatment with the vehicle control (white bar), 5-fluorouracil (5-FU) $(1.75 \mu \mathrm{M})$ alone (light gray bar), depsipeptide (Dep) $(1 \mathrm{nM})$ alone (dark gray bar) and the combination of 5-FU $(1.75 \mu \mathrm{M})+$ Dep $(1 \mathrm{nM})$ (black bar). Data are expressed as relative light units (RLU) $/ \mu \mathrm{g}$ of protein. The $\mathrm{x}$-axis represents the length of the treatment period (h), and the y-axis represents RLU/ $\mu \mathrm{g}$ of protein. ${ }^{*} \mathrm{P}<0.05$ or ${ }^{* *} \mathrm{P}<0.01$ indicates a significant difference. 
Table II. GO analysis for comparison between control and 5-FU (1.75 $\mu \mathrm{M})+$ Dep (1 nM) combination. Top 1,000 genes with upregulation of over 1.5-fold-change.

\begin{tabular}{|c|c|c|c|c|c|c|}
\hline \multirow[b]{2}{*}{ Ontology terms (class ID) } & \multicolumn{2}{|c|}{ F1.75D1 } & \multicolumn{2}{|c|}{ F1.75D0 } & \multicolumn{2}{|c|}{ F0D1 } \\
\hline & $\begin{array}{l}\text { Fold } \\
\text { enrichment }\end{array}$ & P-value & $\begin{array}{l}\text { Fold } \\
\text { enrichment }\end{array}$ & P-value & $\begin{array}{l}\text { Fold } \\
\text { enrichment }\end{array}$ & P-value \\
\hline \multicolumn{7}{|l|}{ PANTHER GO-Slim Biological Process } \\
\hline $\begin{array}{l}\text { Antigen processing and presentation of } \\
\text { peptide or polysaccharide antigen via } \\
\text { MHC class (GO:0002504) }\end{array}$ & 4.98 & $2.42 \mathrm{E}-02$ & 0.56 & $1.00 \mathrm{E}+00$ & $>5.00$ & $3.78 \mathrm{E}-03$ \\
\hline $\begin{array}{l}\text { Phospholipid metabolic process } \\
\text { (GO:0006644) }\end{array}$ & 2.78 & $2.58 \mathrm{E}-03$ & 1.77 & $1.00 \mathrm{E}+00$ & 2.11 & $6.54 \mathrm{E}-01$ \\
\hline $\begin{array}{l}\text { Cellular component morphogenesis } \\
\text { (GO:0032989) }\end{array}$ & 1.98 & $4.08 \mathrm{E}-03$ & 1.66 & $5.20 \mathrm{E}-01$ & 1.21 & $1.00 \mathrm{E}+00$ \\
\hline $\begin{array}{l}\text { Anatomical structure morphogenesis } \\
(\mathrm{GO}: 0009653)\end{array}$ & 1.91 & $1.78 \mathrm{E}-03$ & 1.66 & $1.75 \mathrm{E}-01$ & 1.29 & $1.00 \mathrm{E}+00$ \\
\hline Death (GO:0016265) & 1.86 & 7.23E-03 & 1.21 & $1.00 \mathrm{E}+00$ & 1.32 & $1.00 \mathrm{E}+00$ \\
\hline Cell death (GO:0008219) & 1.83 & $1.19 \mathrm{E}-02$ & 1.18 & $1.00 \mathrm{E}+00$ & 1.33 & $1.00 \mathrm{E}+00$ \\
\hline Apoptotic process (GO:0006915) & 1.77 & $4.59 \mathrm{E}-02$ & 1.21 & $1.00 \mathrm{E}+00$ & 1.32 & $1.00 \mathrm{E}+00$ \\
\hline $\begin{array}{l}\text { Cellular component organization } \\
\text { (GO:0016043) }\end{array}$ & 1.61 & $1.71 \mathrm{E}-03$ & 1.44 & $1.71 \mathrm{E}-01$ & 1.49 & 5.37E-02 \\
\hline $\begin{array}{l}\text { Phosphate-containing compound metabolic } \\
\text { process (GO:0006796) }\end{array}$ & 1.57 & $4.78 \mathrm{E}-02$ & 1.32 & $1.00 \mathrm{E}+00$ & 1.88 & $2.19 \mathrm{E}-05$ \\
\hline $\begin{array}{l}\text { Cellular component organization or } \\
\text { biogenesis (GO:0071840) }\end{array}$ & 1.52 & $9.82 \mathrm{E}-03$ & 1.52 & $1.25 \mathrm{E}-02$ & 1.43 & $1.37 \mathrm{E}-01$ \\
\hline Developmental process (GO:0032502) & 1.41 & $1.22 \mathrm{E}-03$ & 1.25 & $7.35 \mathrm{E}-01$ & 1.25 & $6.68 \mathrm{E}-01$ \\
\hline Cell communication (GO:0007154) & 1.39 & $1.64 \mathrm{E}-04$ & 1.13 & $1.00 \mathrm{E}+00$ & 1.13 & $1.00 \mathrm{E}+00$ \\
\hline Cellular process (GO:0009987) & 1.22 & $2.39 \mathrm{E}-04$ & 1.19 & $5.49 \mathrm{E}-03$ & 1.23 & $1.72 \mathrm{E}-04$ \\
\hline \multicolumn{7}{|l|}{ PANTHER GO-Slim Cellular Component } \\
\hline MHC protein complex (GO:0042611) & $>5.00$ & $2.23 \mathrm{E}-05$ & 1.13 & $1.00 \mathrm{E}+00$ & $>5.00$ & $1.98 \mathrm{E}-05$ \\
\hline $\begin{array}{l}\text { Intermediate filament cytoskeleton } \\
(\mathrm{GO}: 0045111)\end{array}$ & 3.70 & $3.58 \mathrm{E}-03$ & 4.06 & $7.06 \mathrm{E}-04$ & 1.15 & $1.00 \mathrm{E}+00$ \\
\hline Cytoskeleton (GO:0005856) & 2.18 & $4.74 \mathrm{E}-08$ & 1.68 & 8.97E-03 & 1.79 & $9.17 \mathrm{E}-04$ \\
\hline Actin cytoskeleton (GO:0015629) & 2.14 & $1.70 \mathrm{E}-03$ & 1.62 & $6.18 \mathrm{E}-01$ & 1.36 & $1.00 \mathrm{E}+00$ \\
\hline Organelle (GO:0043226) & 1.40 & $4.23 \mathrm{E}-03$ & 1.44 & $1.18 \mathrm{E}-03$ & 1.41 & $3.42 \mathrm{E}-03$ \\
\hline Intracellular (GO:0005622) & 1.28 & $3.67 \mathrm{E}-02$ & 1.32 & $7.91 \mathrm{E}-03$ & 1.22 & $2.77 \mathrm{E}-01$ \\
\hline Cell part (GO:0044464) & 1.25 & 4.49E-02 & 1.35 & $2.80 \mathrm{E}-04$ & 1.17 & $8.30 \mathrm{E}-01$ \\
\hline \multicolumn{7}{|l|}{ PANTHER GO-Slim Molecular Function } \\
\hline $\begin{array}{l}\text { Hydrogen ion transmembrane transporter } \\
\text { activity (GO:0015078) }\end{array}$ & 4.62 & $3.24 \mathrm{E}-02$ & 2.09 & $1.00 \mathrm{E}+00$ & 1.56 & $1.00 \mathrm{E}+00$ \\
\hline Actin binding (GO:0003779) & 2.63 & $9.73 \mathrm{E}-03$ & 2.07 & 7.69E-01 & 1.70 & $1.00 \mathrm{E}+00$ \\
\hline Cytoskeletal protein binding (GO:0008092) & 2.60 & $4.21 \mathrm{E}-04$ & 1.88 & $7.31 \mathrm{E}-01$ & 1.79 & $1.00 \mathrm{E}+00$ \\
\hline $\begin{array}{l}\text { Structural constituent of cytoskeleton } \\
\text { (GO:0005200) }\end{array}$ & 2.06 & $1.11 \mathrm{E}-05$ & 1.59 & $2.26 \mathrm{E}-01$ & 1.42 & $1.00 \mathrm{E}+00$ \\
\hline Protein binding (GO:0005515) & 1.37 & $1.30 \mathrm{E}-03$ & 1.22 & $8.41 \mathrm{E}-01$ & 1.14 & $1.00 \mathrm{E}+00$ \\
\hline Hydrolase activity (GO:0016787) & 1.37 & $1.10 \mathrm{E}-02$ & 1.29 & $2.30 \mathrm{E}-01$ & 1.27 & $5.10 \mathrm{E}-01$ \\
\hline
\end{tabular}

GO, Gene Ontology. F1.75D1, 5-FU $(1.75 \mu \mathrm{M})+$ Dep $(1 \mathrm{nM})$ combination; F1.75D0, 5-FU (1.75 $\mu \mathrm{M})$ alone, F0D1, Dep (1 nM) alone.

of 5-FU and Dep. We examined levels of mRNAs encoded by various genes in the cells treated with 5-FU or Dep alone, and the combination of 5-FU and Dep by qRT-PCR method (Fig. 3).
The levels of TS mRNA encoded by the TYMS gene were decreased by $42 \%$ in the cells treated with the combination of 5-FU and Dep with statistical significance $(\mathrm{P}<0.01)$. 
Table III. GO analysis for comparison between control and 5FU $(1.75 \mu \mathrm{M})+$ Dep $(1 \mathrm{nM})$ combination. Top 1,000 genes with downregulation over 1.5-fold-change.

\begin{tabular}{|c|c|c|c|c|c|c|}
\hline \multirow[b]{2}{*}{ Ontology terms (class ID) } & \multicolumn{2}{|c|}{$\mathrm{F} 1.75 \mathrm{D} 1$} & \multicolumn{2}{|c|}{$\mathrm{F} 1.75 \mathrm{D} 0$} & \multicolumn{2}{|c|}{ F0D1 } \\
\hline & $\begin{array}{l}\text { Fold } \\
\text { enrichment }\end{array}$ & P-value & $\begin{array}{l}\text { Fold } \\
\text { enrichment }\end{array}$ & P-value & $\begin{array}{l}\text { Fold } \\
\text { enrichment }\end{array}$ & P-value \\
\hline \multicolumn{7}{|l|}{ PANTHER GO-Slim Biological Process } \\
\hline Chromatin organization (GO:0006325) & 3.17 & $4.23 \mathrm{E}-07$ & 1.02 & $1.00 \mathrm{E}+00$ & 1.52 & $1.00 \mathrm{E}+00$ \\
\hline Organelle organization (GO:0006996) & 1.99 & $6.67 \mathrm{E}-04$ & 1.11 & $1.00 \mathrm{E}+00$ & 1.19 & $1.00 \mathrm{E}+00$ \\
\hline Cell cycle (GO:0007049) & 1.65 & $1.56 \mathrm{E}-03$ & 1.03 & $1.00 \mathrm{E}+00$ & 1.11 & $1.00 \mathrm{E}+00$ \\
\hline $\begin{array}{l}\text { Cellular component organization } \\
(\mathrm{GO}: 0016043)\end{array}$ & 1.55 & $1.13 \mathrm{E}-02$ & 1.16 & $1.00 \mathrm{E}+00$ & 1.23 & $1.00 \mathrm{E}+00$ \\
\hline $\begin{array}{l}\text { Cellular component organization or } \\
\text { biogenesis (GO:0071840) }\end{array}$ & 1.48 & $3.27 \mathrm{E}-02$ & 1.16 & $1.00 \mathrm{E}+00$ & 1.14 & $1.00 \mathrm{E}+00$ \\
\hline $\begin{array}{l}\text { Transcription from RNA polymerase II } \\
\text { promoter (GO:0006366) }\end{array}$ & 1.43 & $1.80 \mathrm{E}-02$ & 1.20 & $1.00 \mathrm{E}+00$ & 1.61 & $1.41 \mathrm{E}-05$ \\
\hline $\begin{array}{l}\text { Nucleobase-containing compound } \\
\text { metabolic process (GO:0006139) }\end{array}$ & 1.41 & $6.86 \mathrm{E}-06$ & 1.07 & $1.00 \mathrm{E}+00$ & 1.27 & $3.06 \mathrm{E}-02$ \\
\hline RNA metabolic process (GO:0016070) & 1.38 & $6.85 \mathrm{E}-03$ & 1.09 & $1.00 \mathrm{E}+00$ & 1.44 & $3.19 \mathrm{E}-04$ \\
\hline $\begin{array}{l}\text { Transcription, DNA-dependent } \\
\text { (GO:0006351) }\end{array}$ & 1.38 & $3.81 \mathrm{E}-02$ & 1.20 & $1.00 \mathrm{E}+00$ & 1.64 & $4.53 \mathrm{E}-07$ \\
\hline Biological regulation (GO:0065007) & 1.27 & $1.13 \mathrm{E}-02$ & 1.24 & 4.79E-02 & 1.34 & $9.88 \mathrm{E}-05$ \\
\hline Primary metabolic process (GO:0044238) & 1.25 & $1.70 \mathrm{E}-05$ & 1.11 & $1.00 \mathrm{E}+00$ & 1.10 & $1.00 \mathrm{E}+00$ \\
\hline Metabolic process (GO:0008152) & 1.22 & $3.98 \mathrm{E}-06$ & 1.13 & $1.80 \mathrm{E}-01$ & 1.11 & $8.58 \mathrm{E}-01$ \\
\hline Cellular process (GO:0009987) & 1.19 & $1.06 \mathrm{E}-02$ & 1.19 & $9.44 \mathrm{E}-03$ & 1.06 & $1.00 \mathrm{E}+00$ \\
\hline \multicolumn{7}{|l|}{ PANTHER GO-Slim Molecular Function } \\
\hline Chromatin binding (GO:0003682) & 2.87 & $4.26 \mathrm{E}-03$ & 1.48 & $1.00 \mathrm{E}+00$ & 1.75 & $1.00 \mathrm{E}+00$ \\
\hline Nucleic acid binding (GO:0003676) & 1.41 & $8.32 \mathrm{E}-05$ & 0.97 & $1.00 \mathrm{E}+00$ & 1.33 & $6.16 \mathrm{E}-03$ \\
\hline DNA binding (GO:0003677) & 1.40 & $1.67 \mathrm{E}-02$ & 1.09 & $1.00 \mathrm{E}+00$ & 1.54 & $5.30 \mathrm{E}-05$ \\
\hline Binding (GO:0005488) & 1.34 & $2.77 \mathrm{E}-08$ & 1.10 & $1.00 \mathrm{E}+00$ & 1.26 & $6.70 \mathrm{E}-05$ \\
\hline Catalytic activity (GO:0003824) & 1.22 & $1.17 \mathrm{E}-02$ & 1.19 & 8.98E-02 & 1.03 & $1.00 \mathrm{E}+00$ \\
\hline
\end{tabular}

PANTHER GO-Slim Molecular Function

Not extracted

GO, Gene Ontology. F1.75D1, 5-FU $(1.75 \mu \mathrm{M})+$ Dep $(1 \mathrm{nM})$ combination; F1.75D0, 5-FU (1.75 $\mu \mathrm{M})$ alone, F0D1, Dep (1 nM) alone.

Slight, but statistically significant downregulation was observed for HDAC1 mRNA in the cells treated with the 5-FU and Dep combination.

Dep alone and the combination of 5-FU and Dep decreased cellular p16 mRNA levels by 60 and 64\%, respectively.

Regardless of the presence of Dep, 5-FU induced p21 levels; marked changes in p21 levels by $396 \%$ were observed without Dep, and by $764 \%$ with combination of 5-FU and Dep with statistical significance $(\mathrm{P}<0.01)$.

Dep reduced TP53 levels by $75 \%$. 5-FU alone also slightly decreased TP53 levels by $42 \%$.

5-FU considerably decreased the BCL2 mRNA level to $59 \%$, which was apparently restored in the presence of Dep (to $103 \%$ in the combination with 5-FU).

An unremarkable change was observed in BAK1 mRNA in the cells following treatment with either 5-FU alone or Dep alone (138 and $86 \%$, respectively). The combination of these drugs slightly increased the BAK1 mRNA level to $160 \%$, which was statistically significant compared with the vehicle control $(\mathrm{P}<0.05)$, and with Dep only $(\mathrm{P}<0.01)$. Regarding BAX, 5-FU increased the BAX mRNA level to $163 \%$. The combination of Dep with 5-FU decreased BAX mRNA to $49 \%$ of the vehicle control, which was statistically significant compared with 5 -FU only $(\mathrm{P}<0.01)$, and with the vehicle control $(\mathrm{P}<0.05)$.

MHC class II and I mRNA levels in the HCT-116 cells following treatment with 5-FU (1.75 $\mu \mathrm{M})$ alone, Dep (1 nM) alone, and a combination of 5-FU and Dep. We examined levels of MHC class II and I mRNA by qRT-PCR in the cells treated with 5-FU or Dep alone, and a combination of 5-FU and Dep (Fig 4).

MHC class II genes, including $H L A-D P B 1, H L A-D Q B 1$, $H L A-D R A$, and $H L A-D R B 1$ were markedly upregulated 



Figure 3. The mechanism of action, cell cycle- and apoptosis-related gene-expression in HCT-116 cells following treatment with the vehicle control (F-D), 5-fluorouracil (5-FU) $(1.75 \mu \mathrm{M})$ alone $\left(\mathrm{F}^{+} \mathrm{D}^{-}\right)$, depsipeptide (Dep) $(1 \mathrm{nM})$ alone $\left(\mathrm{F}^{-} \mathrm{D}^{+}\right)$and the combination of 5-FU $(1.75 \mu \mathrm{M})+\mathrm{Dep}(1 \mathrm{nM})\left(\mathrm{F}^{+} \mathrm{D}^{+}\right)$. mRNA levels were assessed by qRT-PCR and were normalized by the ACTB mRNA level at each point. The y-axis represents mRNA levels of the genes of interest relative to ACTB mRNA. Data are expressed as mean \pm SEM. ${ }^{*} \mathrm{P}<0.05$ or ${ }^{* * *} \mathrm{P}<0.01$ indicates a significant difference by one-way ANOVA.

in combination with 5-FU and Dep $(\mathrm{P}<0.01)$ to 432,298 , 667 and $847 \%$, respectively, compared to the vehicle controls.

Dep alone slightly increased levels of MHC class II genes, including $H L A-D P B 1, H L A-D Q B 1, H L A-D R A$, and $H L A-D R B 1$ by $52,38,157$ and $168 \%$, respectively. Compared with Dep alone, the combination with 5-FU greatly elevated mRNA levels of these MHC class II genes, namely, $H L A-D P B 1, H L A-D Q B 1, H L A-D R A$, and HLA-DRB1 with statistical significance $(\mathrm{P}<0.01)$. In the HT29 and SW48 cells, increased expression level of HLA-DRA (MHC class II gene) was observed with statistical significance in combination of 5-FU and Dep by real-time PCR (data not shown).
No change in the levels of MHC class I genes including $H L A-A, H L A-B-H L A-C$ were observed following treatment with 5-FU, Dep, or 5-FU plus Dep.

Summary of changes in expression of molecular regulation of MHC class II genes by microarray analysis in the HCT-116 cells. We further analyzed the results of our global analysis of gene expression, which were focused on genes involved in the molecular regulation of MHC class II genes. As described in Table IV, we found the highest degree of increased expression levels of PCAF, CREB3, CREB5, and CIITA after the combination of 5-FU and Dep. PCAF, a histone acetyltrans- 


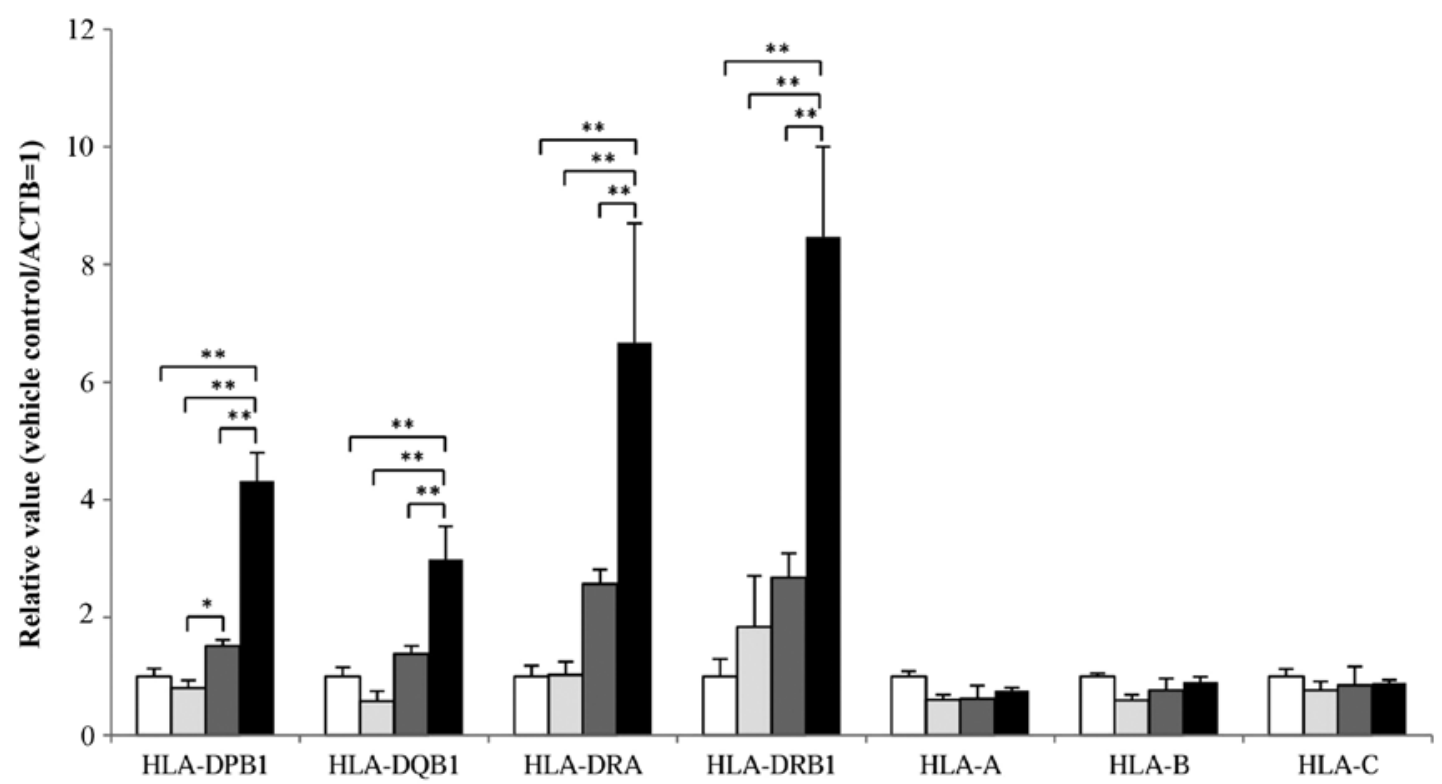

Figure 4. Expression of major histocompatibility complex (MHC) class II and I genes in the HCT-116 cells following treatment with the vehicle control (white bar), 5-fluorouracil (5-FU) $(1.75 \mu \mathrm{M})$ alone (light gray bar), depsipeptide (Dep) (1 nM) alone (dark gray bar), and the combination of 5-FU (1.75 $\mu \mathrm{M})+$ Dep $(1 \mathrm{nM})$ (black bar). The mRNA levels were normalized by the ACTB mRNA level at each point. The x-axis indicates the MHC class II and MHC class I genes. The $\mathrm{y}$-axis represents mRNA levels of the genes of interest relative to the ACTB mRNA. Data are expressed as mean \pm SEM. ${ }^{*} \mathrm{P}<0.05$ or ${ }^{* *} \mathrm{P}<0.01$ indicates a significant difference by one-way ANOVA.

Table IV. Summary of changes in gene expression for molecular regulation of MHC class II genes by microarray analysis in the HCT-116 cells.

Gene name

(synonym)

Accession no.

Description

Fold-change

\begin{tabular}{|c|c|c|c|c|c|}
\hline CIITA & NM_000246 & Class II, major histocompatibility complex, transactivator & 2.80 & 0.80 & 0.91 \\
\hline CREB1 & NM_13444 & cAMP responsive element binding protein 1 & 0.91 & 0.91 & 1.17 \\
\hline CREB2 (ATF4) & NM_001675 & Activating transcription factor 4 & 0.22 & 0.66 & 0.55 \\
\hline CREB3 & NM_006368 & cAMP responsive element binding protein 3 & 2.13 & 1.05 & 1.09 \\
\hline CREB5 & NM_182898 & cAMP responsive element binding protein 5 & 6.51 & 0.75 & 0.64 \\
\hline EP300 (KAT3B) & NM_001429 & E1A binding protein $\mathrm{p} 300$ & 0.59 & 0.69 & 0.80 \\
\hline KAT2B (PCAF) & NM_003884 & $\mathrm{K}$ (lysine) acetyltransferase $2 \mathrm{~B}$ & 3.15 & 1.37 & 1.47 \\
\hline NFYA & NM_002505 & Nuclear transcription factor $\mathrm{Y}, \alpha$ & 1.27 & 1.02 & 1.15 \\
\hline NFYB & NM_006166 & Nuclear transcription factor $\mathrm{Y}, \beta$ & 0.88 & 1.14 & 0.97 \\
\hline NFYC & NM_014223 & Nuclear transcription factor $\mathrm{Y}, \gamma$ & 0.56 & 1.08 & 0.87 \\
\hline PCBP4 (CBP) & NM_033010 & poly $(\mathrm{rC})$ binding protein 4 & 1.43 & 1.05 & 1.10 \\
\hline RFXANK & NM_003721 & Regulatory factor $\mathrm{X}$-associated ankyrin-containing protein & 0.37 & 0.63 & 0.68 \\
\hline RFXAP & NM_000538 & Regulatory factor $\mathrm{X}$-associated protein & 1.29 & 0.82 & 0.79 \\
\hline $\mathrm{RX} 5$ & NM_000449 & Regulatory factor X, 5 (influences HLA class II expression) & 0.95 & 1.51 & 0.97 \\
\hline
\end{tabular}

MHC, major histocompatibility complex. F1.75D1, 5-FU (1.75 $\mu \mathrm{M})+$ Dep (1 nM) combination; F1.75D0, 5-FU (1.75 $\mu \mathrm{M})$ alone, F0D1, Dep $(1 \mathrm{nM})$ alone.

ferase, is related to apoptotic cell processes, and CREB3, CREB5 and CIITA are related to MHC class II gene expression. On the contrary, ATF4, a member of the CREB family, was slightly downregulated following treatment with 5-FU or Dep alone, and markedly downregulated by the combination of 5-FU and Dep.

\section{Discussion}

In the present study, we found the HDAC inhibitor, Dep, potentiated 5-FU cytotoxicity via inhibition of colony formation ability in human colon cancer HCT-116 cells (Fig. 1). The primary findings of our study were that Dep augments 
the effects of 5-FU in HCT-116 cells, and that activation of caspase-3/7 is the underlying mechanism. Moreover, the importance of MHC class II and p21 (CDKN1A) upregulation (Figs. 4 and 3, respectively) in the effect of the combination of 5-FU and Dep was revealed. Dep was previously reported to induce caspase-dependent apoptosis in small cell lung cancer cells via the mitochondrial pathway by suppressing the expression of BCL2 family members (28). In contrast, the present study did not show a marked reduction in HCT-116 cells. These results indicated that the sensitization of HCT-116 cells to the combination of 5-FU and Dep was not likely to be mediated by changes in expression of BCL2 family members (28).

Exposure of cancer cells to 5-FU elevated the expression of p21 (CDKN1A), and the combination of Dep with 5-FU further enhanced this mRNA expression of p21 (CDKN1A) (Fig. 3). Induction of $\mathrm{p} 21$ using a tetracycline-inducible vector system showed that p21 plays an important role in the induction of growth arrest in tumor cells (29). A critical role of p21 has been described as a critical mediator of cytotoxicity of 5-FU (30). These results are consistent with our present results that the 5-FU-induced and Dep-enhanced p21 (CDKN1A) expression are both associated with cell cycle arrest.

Our present microarray and the successive gene ontology analyses revealed that combination of 5-FU and Dep markedly increased the mRNA levels of MHC class II genes, namely, $H L A-D P B 1, H L A-D Q B 1, H L A-D R A$, and HLA-DRBl (Fig. 4). This marked activation of MHC class II gene expression, however, was not noted following treatment with $1.75 \mu \mathrm{M}$ 5-FU alone, or $1 \mathrm{nM}$ depsipeptide alone. The HCT-116 cells treated with the combination underwent caspase 3/7-associated apoptosis. Therefore, activation of MHC class II expression may have some relationship with the cell apoptotic process. Ting and Trowsdale described positively regulated control of MHC class II expression, which was mediated by DNA binding factors including NF-Y, CREB, and RFX, and the coactivator, CIITA, general transcription factors, and histone acetyltransferases including P300/CBP-associated factor (PCAF) (31). Among them, PCAF was reported to accelerate cancer cell apoptosis by counteracting the anti-apoptotic cellular process (32). In addition, an HDAC inhibitor was reported to enhance MHC class II expression in both CIITA-dependent and -independent manners (33). Our present results of augmentation of MHC class II gene expression after the treatment with 5-FU combined with an HDAC inhibitor, depsipeptide, may be collateral antitumor events for the induction of cellular apoptosis by 5-FU. Our global analysis of gene expression indicated marked induction of MHC class II members together with PCAF (also called KAT2B), CREB3, CREB5, and CIITA (Table IV), which may be correlated with a number of apoptotic cell processes, by the combination of 5-FU and depsipeptide. In fact, higher 5-FU concentrations revealed dose-dependent MHC class II induction (unpublished data). Collectively, our present results may indicate a closer relationship between the elevation of MHC class II expression and cellular apoptosis induced by antitumor agent, 5-FU. Furthermore, we are investigating whether induction of MHC class II proteins after 5-FU-based chemotherapy is a prognostic marker.

On the other hand, previous reports have documented the importance of histone acetylation as a positive regulator of
MHC class II transcription and that HDAC inhibitors augment the expression of tumor cell MHC class II (34-36). Dep may affect the differentiation of colon cancer cells because of the close correlation already shown between the expression of $H L A-D R$ antigen and the differentiation of tumor cells using gastric carcinoma models $(37,38)$.

West et al recently proposed that HDAC inhibitors require the immune system to exert their anticancer effects (39). Downregulation of immune-system-related genes including MHC class II genes was shown to associate cooperatively with the metastatic potential of early stage colorectal carcinoma (40).

Our present results are in agreement with concepts raised very recently that immune systems where MHC class II genes are involved have a considerable relationship with successful cancer chemotherapy and/or less cancer cell malignancies.

Therefore, our present results imply that 5-FU combined with Dep synergistically enhances the expression of tumor cell surface immunological proteins (i.e., marked inductions of MHC class II genes). This is consistent with what is known concerning the concerted mechanisms of therapeutic drugs and immune systems in cancer chemotherapy.

In conclusion, the combination of 5-FU and Dep sensitized human colon cancer HCT-116, HT29, and SW48 cells. The sensitization in the HCT-116 cells likely occurred through apoptosis induction shown by caspase-3/7 activation, induction of cell cycle arrest shown by p21 (CDKN1A) upregulation, and induction of MHC class II gene expression. MHC class II gene induction may render cancer chemotherapy more effective through a possible cooperation of the immune system with cancer chemotherapy. Epigenetic modulation of existing anticancer drugs may be considered for development of novel cancer chemotherapy.

\section{Acknowledgements}

We wish to thank Editage (www.editage.jp) for English language editing.

\section{References}

1. Longley DB, Harkin DP and Johnston PG: 5-fluorouracil: Mechanisms of action and clinical strategies. Nat Rev Cancer 3: 330-338, 2003.

2. Gustavsson B, Carlsson G, Machover D, Petrelli N, Roth A Schmoll HJ, Tveit KM and Gibson F: A review of the evolution of systemic chemotherapy in the management of colorectal cancer. Clin Colorectal Cancer 14: 1-10, 2015.

3. Meyerhardt JA and Mayer RJ: Systemic therapy for colorectal cancer. N Engl J Med 352: 476-487, 2005.

4. Tsai HC and Baylin SB: Cancer epigenetics: Linking basic biology to clinical medicine. Cell Res 21: 502-517, 2011.

5. Dokmanovic M, Clarke C and Marks PA: Histone deacetylase inhibitors: Overview and perspectives. Mol Cancer Res 5: 981-989, 2007.

6. Prince HM, Bishton MJ and Harrison SJ: Clinical studies of histone deacetylase inhibitors. Clin Cancer Res 15: 3958-3969, 2009.

7. Minucci S and Pelicci PG: Histone deacetylase inhibitors and the promise of epigenetic (and more) treatments for cancer. Nat Rev Cancer 6: 38-51, 2006.

8. Liu S, Cheng H, Kwan W, Lubieniecka JM and Nielsen TO: Histone deacetylase inhibitors induce growth arrest, apoptosis, and differentiation in clear cell sarcoma models. Mol Cancer Ther 7: 1751-1761, 2008.

9. Bots $\mathrm{M}$ and Johnstone RW: Rational combinations using HDAC inhibitors. Clin Cancer Res 15: 3970-3977, 2009. 
10. Iwahashi S, Shimada M, Utsunomiya T, Morine Y, Imura S, Ikemoto T, Mori H, Hanaoka J and Saito Y: Histone deacetylase inhibitor enhances the anti-tumor effect of gemcitabine: A special reference to gene-expression microarray analysis. Oncol Rep 26: 1057-1062, 2011.

11. Subramaniam D, Thombre R, Dhar A and Anant S: DNA methyltransferases: A novel target for prevention and therapy. Front Oncol 4: 80, 2014.

12. Glaser KB: HDAC inhibitors: Clinical update and mechanism-based potential. Biochem Pharmacol 74: 659-671, 2007.

13. Humeniuk R, Mishra PJ, Bertino JR and Banerjee D: Epigenetic reversal of acquired resistance to 5-fluorouracil treatment. Mol Cancer Ther 8: 1045-1054, 2009.

14. Keshelava N, Davicioni E, Wan Z, Ji L, Sposto R, Triche TJ and Reynolds CP: Histone deacetylase 1 gene expression and sensitization of multidrug-resistant neuroblastoma cell lines to cytotoxic agents by depsipeptide. J Natl Cancer Inst 99: 1107-1119, 2007.

15. Thurn KT, Thomas S, Moore A and Munster PN: Rational therapeutic combinations with histone deacetylase inhibitors for the treatment of cancer. Future Oncol 7: 263-283, 2011.

16. Stiborová M, Eckschlager T, Poljaková J, Hraběta J, Adam V, Kizek R and Frei E: The synergistic effects of DNA-targeted chemotherapeutics and histone deacetylase inhibitors as therapeutic strategies for cancer treatment. Curr Med Chem 19 4218-4238, 2012

17. Ikehata M, Ogawa M, Yamada Y, Tanaka S, Ueda K and Iwakawa S: Different effects of epigenetic modifiers on the cytotoxicity induced by 5-fluorouracil, irinotecan or oxaliplatin in colon cancer cells. Biol Pharm Bull 37: 67-73, 2014.

18. Ueda H, Nakajima H, Hori Y, Fujita T, Nishimura M, Goto T and Okuhara M: FR901228, a novel antitumor bicyclic depsipeptide produced by Chromobacterium violaceum No. 968. I. Taxonomy, fermentation, isolation, physico-chemical and biological properties, and antitumor activity. J Antibiot (Tokyo) 47: 301-310, 1994

19. Ueda H, Nakajima H, Hori Y, Goto T and Okuhara M: Action of FR901228, a novel antitumor bicyclic depsipeptide produced by Chromobacterium violaceum no. 968 , on Ha-ras transformed NIH3T3 cells. Biosci Biotechnol Biochem 58: 1579-1583, 1994.

20. Furumai R, Matsuyama A, Kobashi N, Lee KH, Nishiyama M, Nakajima H, Tanaka A, Komatsu Y, Nishino N, Yoshida M, et al: FK228 (depsipeptide) as a natural prodrug that inhibits class I histone deacetylases. Cancer Res 62: 4916-4921, 2002.

21. Lee JH, Park JH, Jung Y, Kim JH, Jong HS, Kim TY and Bang YJ: Histone deacetylase inhibitor enhances 5-fluorouracil cytotoxicity by down-regulating thymidylate synthase in human cancer cells. Mol Cancer Ther 5: 3085-3095, 2006.

22. Tumber A, Collins LS, Petersen KD, Thougaard A Christiansen SJ, Dejligbjerg M, Jensen PB, Sehested M and Ritchie JW: The histone deacetylase inhibitor PXD101 synergises with 5-fluorouracil to inhibit colon cancer cell growth in vitro and in vivo. Cancer Chemother Pharmacol 60: 275-283, 2007.

23. Di Gennaro E, Bruzzese F, Pepe S, Leone A, Delrio P, Subbarayan PR, Avallone A and Budillon A: Modulation of thymidilate synthase and p53 expression by HDAC inhibitor vorinostat resulted in synergistic antitumor effect in combination with 5FU or raltitrexed. Cancer Biol Ther 8: 782-791, 2009.

24. Fazzone W, Wilson PM, Labonte MJ, Lenz HJ and Ladner RD: Histone deacetylase inhibitors suppress thymidylate synthase gene expression and synergize with the fluoropyrimidines in colon cancer cells. Int J Cancer 125: 463-473, 2009.
25. Wolter F, Akoglu B, Clausnitzer A and Stein J: Downregulation of the cyclin D1/Cdk4 complex occurs during resveratrol-induced cell cycle arrest in colon cancer cell lines. J Nutr 131: 2197-2203, 2001.

26. Lowry OH, Rosebrough NJ, Farr AL and Randall RJ: Protein measurement with the Folin phenol reagent. J Biol Chem 193: 265-275, 1951.

27. Mi H, Muruganujan A and Thomas PD: PANTHER in 2013: Modeling the evolution of gene function, and other gene attributes, in the context of phylogenetic trees. Nucleic Acids Res 41: D377-D386, 2013.

28. Doi S, Soda H, Oka M, Tsurutani J, Kitazaki T, Nakamura Y, Fukuda M, Yamada Y, Kamihira S and Kohno S: The histone deacetylase inhibitor FR901228 induces caspase-dependent apoptosis via the mitochondrial pathway in small cell lung cancer cells. Mol Cancer Ther 3: 1397-1402, 2004.

29. Fang L, Igarashi M, Leung J, Sugrue MM, Lee SW and Aaronson SA: p21Waf1/Cip1/Sdi1 induces permanent growth arrest with markers of replicative senescence in human tumor cells lacking functional p53. Oncogene 18: 2789-2797, 1999.

30. Geller JI, Szekely-Szucs K, Petak I, Doyle B and Houghton JA: P21Cip1 is a critical mediator of the cytotoxic action of thymidylate synthase inhibitors in colorectal carcinoma cells. Cancer Res 64: 6296-6303, 2004.

31. Ting JP and Trowsdale J: Genetic control of MHC class II expression. Cell 109 (Suppl): S21-S33, 2002.

32. Gai X, Tu K, Li C, Lu Z, Roberts LR and Zheng X: Histone acetyltransferase PCAF accelerates apoptosis by repressing a GLI1/BCL2/BAX axis in hepatocellular carcinoma. Cell Death Dis 6: e1712, 2015.

33. Magner WJ, Kazim AL, Stewart C, Romano MA, Catalano G, Grande C, Keiser N, Santaniello F and Tomasi TB: Activation of MHC class I, II, and CD40 gene expression by histone deacetylase inhibitors. J Immunol 165: 7017-7024, 2000.

34. Beresford GW and Boss JM: CIITA coordinates multiple histone acetylation modifications at the HLA-DRA promoter. Nat Immunol 2: 652-657, 2001.

35. Masternak K and Reith W: Promoter-specific functions of CIITA and the MHC class II enhanceosome in transcriptional activation. EMBO J 21: 1379-1388, 2002.

36. Niesen MI and Blanck G: Rescue of major histocompatibility DR surface expression in retinoblastoma-defective, non-small cell lung carcinoma cells by the MS-275 histone deacetylase inhibitor. Biol Pharm Bull 32: 480-482, 2009.

37. Ma XC, Hattori T, Kushima R, Terata N and Kodama M Expression of HLA-class II antigen in gastric carcinomas. Its relationship to histopathological grade, lymphocyte infiltration and five-year survival rate. Acta Oncol 33: 187-190, 1994.

38. Ishigami $S$, Aikou $T$, Natsugoe $S$, Hokita $S$, Iwashige $H$, Tokushige $M$ and Sonoda $S$ : Prognostic value of HLA-DR expression and dendritic cell infiltration in gastric cancer. Oncology 55: 65-69, 1998.

39. West AC, Smyth MJ and Johnstone RW: The anticancer effects of HDAC inhibitors require the immune system. OncoImmunology 3: e27414, 2014.

40. Fehlker M, Huska MR, Jöns T, Andrade-Navarro MA and Kemmner W: Concerted down-regulation of immune-system related genes predicts metastasis in colorectal carcinoma. BMC Cancer 14: 64-75, 2014. 